\title{
Physical activity and overweight/obesity among academic stressed adolescents
}

\author{
Chunmei Li, ${ }^{1,3}$ Zhaokang Yuan, ${ }^{3}$ Kristen Clements-Nolle, ${ }^{2}$ You Fu, ${ }^{2}$ Melissa Deadmond, ${ }^{2}$ Wei Yang ${ }^{2,3}$ \\ 'Shaanxi Province Jiaotong Hospital, Xi'an, Shaanxi, 7I000I, PR, China \\ ${ }^{2} S$ chool of Community Health Sciences, University of Nevada, Reno, USA \\ ${ }^{3}$ School of Public Health, Nanchang University, Nanchang, Jiangxi 330006, PR, China
}

Correspondence: Wei Yang, University of Nevada, Reno, School of Community Health Sciences, Reno, NV, USA,

Email address: weiyang@unr.edu

Note: Chunmei Li and Zhaokang Yuan are co-first authors for this work.

Received: August 23, 2018 | Published: September 03, 2018

Copyright@ $2018 \mathrm{Li}$ et al. This is an open access article distributed under the terms of the Creative Commons Attribution License, which permits unrestricted use, distribution, and reproduction in any medium, provided the original author and source are credited.

\begin{abstract}
Objectives: This study investigated the relationship between physical activity level and overweight/obesity among academically-stressed Chinese middle school students.

Methods: One thousand eight hundred and ten $(1,810)$ high school students were recruited from the 10th-12th grades $(805$ girls and 1005 boys) from a highschool located in Jiangxi Province of China. Students' risk behaviors were assessed using the Youth Risk Behavior Survey. The Kruskal-Wallis H test and ordinal regression model analysis were employed to identify the relationship between physical activity, academic stress and overweight/obesity.
\end{abstract}

Results: The Kruskal-Wallis H test and ordinal regression model analysis indicated a statistically significant correlation between academic stress and overweight/ obesity among Chinese adolescents, and perhaps physical inactivity is a mediator of this association.

Conclusion: Low physical activity and increasing obesity trajectories among Chinese high school adolescents have become a concern in China; thus, it is imperative to promote participation in physical activity and to build a long-standing mechanism to improve the overall health condition of youths.

Keywords: physical inactivity, youth behavior, academic stress, overweight/obesity

\section{Introduction}

It has been recommended that school-aged children and adolescents should accumulate at least 60 minutes of moderate to vigorous intensity level of physical activity (MVPA) per day for health benefits. ${ }^{1}$ Traditionally, the foremost objective of studies reporting on levels and patterns of physical activity performed by adolescents has been to determine the amount of coherence between recommended and actual MVPA levels. However, data suggest that the majority of youth do not meet these guidelines. Specifically, more than $80 \%$ of adolescents spend less than 60 min of MVPA per day. ${ }^{2}$

In recent years, there has been a decline in the physical activity levels of Chinese adolescents. ${ }^{3}$ Researchers have claimed that the most basic and direct reason for a decline in fitness is insufficient physical activity. ${ }^{4,5}$ Participation in physical activity is not only associated with the external environment factors but is also related to attitude towards an activity or sport. ${ }^{6,7}$

With the increasingly fierce competition, the employment pressure is becoming more and more serious, brings more academic stress and pressure of getting into a key university to high school students. Previous studies have suggested that a proper amount of physical activity time can effectively reduce stress to a certain extent, eliminate fatigue, and maintain optimal mood for learning. In addition, proper levels of physical activity can improve concentration, attention, and on-task behavior. Although the benefits of physical activity are obvious, why are Chinese high school students' physical fitness levels declining?

High school students are the hope and the future of our society, but their physical health condition is becoming worse, which has already caused or will cause certain negative impacts on their current and future well-being. ${ }^{8}$ The primary objective of this study was to determine the prevalence and investigate factors associated with daily health behaviors and physical activity in high school students in China. The relationships between overweight/obesity or academic stress and physical activity levels were investigated. It was hypothesized that the results of this study would show further evidence of an emerging threats of obesity, academic stress, and inadequate physical activity in high school students in China while also showing novel correlations between these outcomes and diverse causes of fitness decline in this context.

\section{Methods}

\section{Setting and data source}

A group of $10^{\text {th }}$ grade and $11^{\text {th }}$ grade students enrolled in a high school in Jiangxi Province was recruited in this study. This was a cross-
Citation: Li C,Yuan Z, Clements-Nolle K, et al. Physical activity and overweight/obesity among academic stressed adolescents. Biostatistics Epidemiol Int J. (20I8); I (2):40-46. DOI: I0.3088 I/beij.000 I I 
sectional study, and a questionnaire was used to assess their health risk behaviors. We did not survey $12^{\text {th }}$ graders because their study time for the entrance examination was too valuable to disrupt. Students in this study came from urban and rural areas. A total of 1900 questionnaires were initially administrated, removing the five students who had left the school or were absent; the rest of the students participated in the questionnaire. A total of 1810 questionnaires were completed and returned, for a response rate of $95.26 \%$.

\section{Questionnaire design}

The Youth Risk Behavioral Surveillance System Survey (YRBSS) was used to assess participants' risk behaviors. This survey is a biennial state-based epidemiologic surveillance system coordinated by the U.S. Centers for Disease Control and Prevention (CDC). ${ }^{9}$ Questions were modified to reflect Chinese culture. The survey consisted of 84 questions in eight categories: (1) Demographic characteristics; (2) Harm behavior; (3) Smoking behavior; (4) Drinking behavior; (5) Eating behavior and body weight; (6) Physical activity; (7) Sexual behavior and other health-related behaviors; (8) Academic stress. The survey was administered to each class as a unit. Students were asked to answer the questions anonymously and independently, and the questionnaires were collected immediately following completion.

\section{Study variables}

Physical activity, time spent studying, and academic performance

Table I Description of specific health risk behaviors and categorizations. students were asked three questions to assess their level of physical activity, time spent studying, and academic performance (Table 1). For physical activity, students could respond " $0,1,2,3,4,5$, 6 , or 7 days". These were recoded as "sedentary time," "light intensity," "moderate intensity," and "vigorous intensity" in order to analyze the influence of physical activity. ${ }^{10-12}$ For time spent studying, students could respond "less than 7 hours", 7 hours, 8 hours, 9 hours, or 10 or more hours" per day. These were recoded as "short time" for 7 hours or less and "long time" for 8 or more hours per day (Table 1). For academic performance, students were asked what their grades were over the past 12 months. Students could respond "mostly A's, B's, C's, D's, E's" or "Other grades." These were recoded as "good grades" for mostly A's or B's, “Average grades" for mostly C's or D's, "Poor grades" for mostly E's, and "None of these grades/not sure" for responses of "other grades" (Table 1).

\section{Academic stress}

Two questions were designed to assess students' academic stress level and source of stress, respectively: (1) "What level of stress do you feel as a result of your studies?" (2) "What is the primary reason for your stress?" For question 1, students could answer "very stressed", "above average stress", "average stress", "below average stress" or "no stress." For question 2, students could select more than one answer from the answer choices: "exams," "getting into a key university," "parents," "teachers," "yourself," and "other." The number distribution of the answers to Question 2 has been shown in Figure 1.

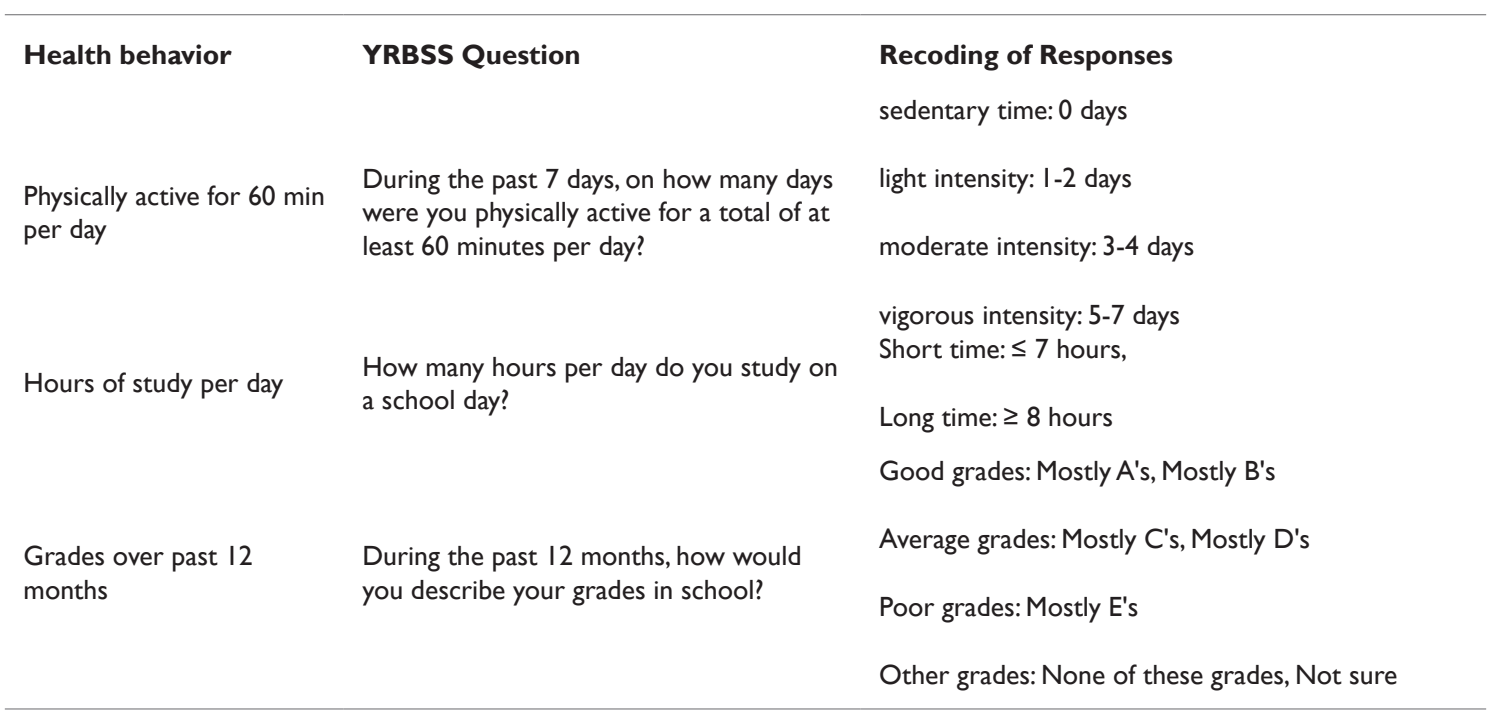

\section{Body Mass Index}

Body Mass Index (BMI) is a body composition measure that is derived from weight and height $\left(\mathrm{kg} / \mathrm{m}^{2}\right)$ of an individual. The BMI attempts to quantify the amount of tissue mass (muscle, fat, and bone) and is then categorize the individual into different weight zones: "underweight," "normal weight," "overweight," or "obese." In this study, high school students' weight and height were self-reported. BMI was then calculated and categorized into a weight zone using Chinese youth BMI criteria (Table 2).

\section{Quality control}

Both the sample selection and the questionnaire survey for this study were conducted in strict accordance with the design plan. The questionnaire was designed for the specific needs of this study based on the United States CDC YRBSS questionnaire by professors from the University of Nevada, Reno in the U.S., and Nanchang University in China. Qualified and trained graduate students from the two institutions implemented and conducted the survey. In addition, teachers at the high school were trained to use the same language when explaining the directions to students. The survey was completed independently by students based on their own understanding of the questions in order to avoid introducing bias. Investigators and data collectors participated in a debriefing meeting to examine the data, and logical verification of the responses was conducted to help ensure data accuracy. 


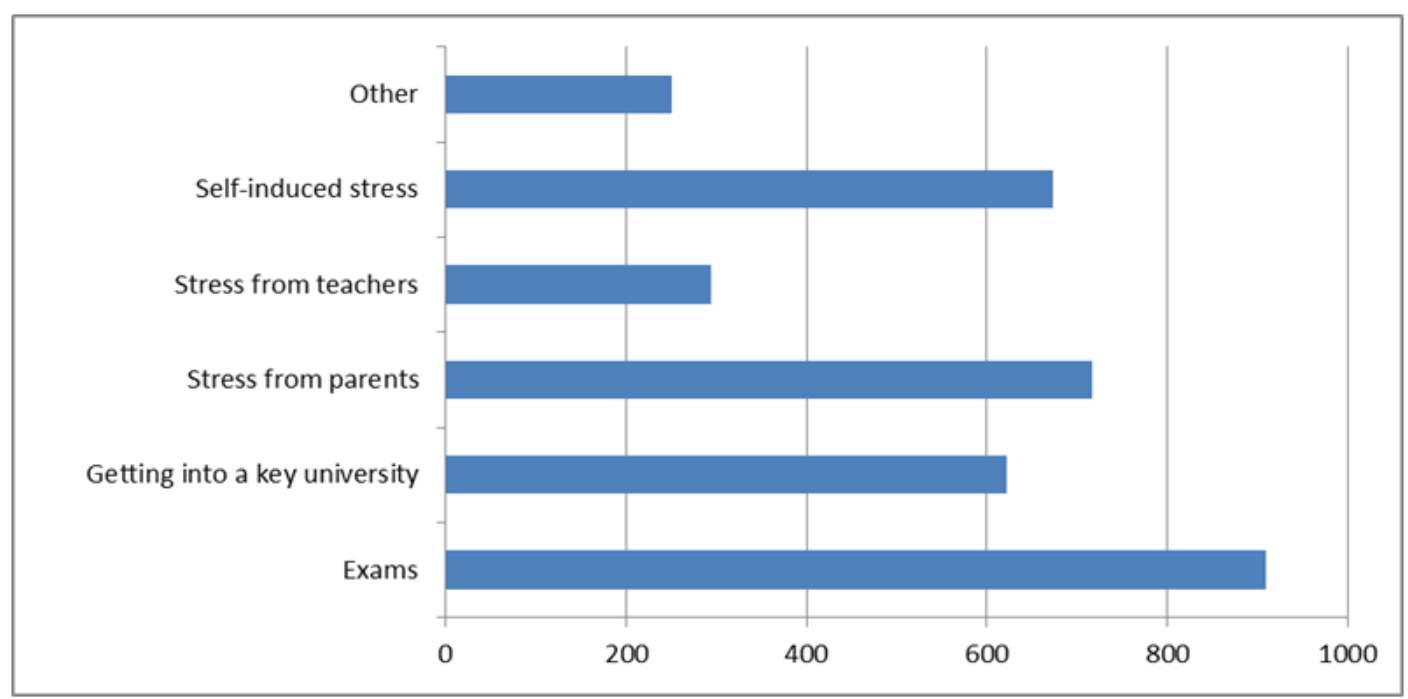

Figure I The number distribution of the answers to the primary reason for academic stress

Table 2 Chinese cut off points for body mass index for overweight and obesity by sex between 7 and 18 years.

\begin{tabular}{lllll}
\hline Age & Male & \multicolumn{3}{c}{ Female } \\
\hline $7 \sim$ & Overweight & Obese & Overweight & Obese \\
\hline $8 \sim$ & 17.4 & 19.2 & 17.2 & 18.9 \\
9 & 18.1 & 20.3 & 18.1 & 19.9 \\
10 & 19.6 & 21.4 & 19.0 & 21.0 \\
II & 20.3 & 22.5 & 20.0 & 22.1 \\
12 & 21.0 & 23.6 & 21.1 & 23.3 \\
13 & 21.9 & 24.7 & 21.9 & 24.5 \\
14 & 22.6 & 25.7 & 22.6 & 25.6 \\
I5 & 23.1 & 26.4 & 23.0 & 26.3 \\
16 & 23.5 & 26.9 & 23.4 & 26.9 \\
I7 & 23.8 & 27.4 & 23.7 & 27.4 \\
18 & 24.0 & 27.8 & 23.8 & 27.7 \\
\hline
\end{tabular}

\section{Statistical analyses}

A database of the survey responses was created using EpiData 3.1 software. SPSS Version 20.0 (IBM Corp., Armonk, NY, USA) was then employed for descriptive and statistical analyses. A descriptive analysis was conducted to describe the sample characteristics. Wilcoxon rank sum test and Kruskal-Wallis $H$ test were then used for the single factor analysis. Ordinal regression was conducted for the multi-factor analysis. The significance level was set at 0.05 for all statistical analyses.

\section{Results}

\section{Demographic data}

Of the 1810 total senior high school students in the study, 1005 (55.5\%) were male and $805(44.5 \%)$ were female. The students were rarely under 14 years old $(n=5,0.3 \%)$. Ninety-one $(5.0 \%)$ students were 15 years old, $553(30.6 \%)$ were 16 years old, $867(47.9 \%)$ were 17 years old, and $294(16.2 \%)$ were 18 years or older. Most of the students $(81.0 \%)$ come from the countryside, while $19.0 \%$ of the students were from the town. Nearly half of the students were living with both parents $(45.5 \%, \mathrm{n}=824)$ or in the school dormitory $(45.5 \%, \mathrm{n}=824)$; students rarely lived with other family/relatives $(\mathrm{n}=135,7.5 \%)$, with other students $(\mathrm{n}=12,0.7 \%)$, or in a house by themselves $(\mathrm{n}=15,0.8 \%)$. There were 874 (48.3\%) students whose father, mother or both parents leave for work. Forty-three-point-four percent of students' education track was science, and $56.6 \%$ of students' education track was arts (Table 3).

\section{Related demographic or behavior characteristics of different levels of youth physical activity}

The Kruskal-Wallis $H$ test was employed to examine the differences on students' demographic or behavior characteristics, and physical activity level. The results indicated that students' height, weight, gender, BMI, weight classification, learning time, and academic stress were significantly correlated with physical activity level (Table 4).

\section{Estimation of ordinal regression model on physical activity influential factors}

The model structure is depicted in three sections: Physical activity was classified into sedentary time, light intensity, moderate intensity and vigorous intensity as the dependent variable, the gender, BMI classification, learning time, and academic stress were as the independent variables, using Logit as link function and assigning them to variables (Table 5).

The likelihood ratio test of the model showed that ordinal regression model was significant, and the test of the parallel line means the fitting model has statistical significance. The model showed that there was a statistically significant influence of gender, BMI classification, time spent learning, and level of academic stress on physical activity level. Girls spent less time participating in physical activity than boys did. Students who spend more time on learning tended to be less physically
Citation: Li C, Yuan Z, Clements-Nolle K, et al. Physical activity and overweight/obesity among academic stressed adolescents. Biostatistics Epidemiol Int J. (20 I8); I (2):40-46. DOI: I0.3088 I/beij.000 I I 
active. A negative relationship was found between physical activity and academic stress; in other words, students who had a lower level of academic stress tended to have a higher physical activity level.

Table 3 Demographic characteristics of the sample, number $(n)$ and percentages (\%).

\begin{tabular}{|c|c|c|c|}
\hline Characteristic & Female $(n, \%)$ & Male (n,\%) & All $(n, \%)$ \\
\hline \multicolumn{4}{|l|}{ Age } \\
\hline 14 years old or young & $4(0.5)$ & $I(0.1)$ & $5(0.3)$ \\
\hline 15 years old & $44(5.5)$ & $47(4.7)$ & $91(5.0)$ \\
\hline 16 years old & $250(31.1)$ & $303(30.1)$ & $553(30.6)$ \\
\hline 17 years old & $373(46.3)$ & $494(49.2)$ & $867(47.9)$ \\
\hline 18 years old or older & $134(16.6)$ & $160(15.9)$ & $294(16.2)$ \\
\hline \multicolumn{4}{|l|}{ Place of residence } \\
\hline Rural & $65 I(80.9)$ & $816(81.2)$ & $\mid 467(8 \mid .0)$ \\
\hline Urban & $154(19.1)$ & $189(18.8)$ & $343(19.0)$ \\
\hline \multicolumn{4}{|l|}{ Living arrangement } \\
\hline With parents & $336(41.7)$ & $488(48.6)$ & $824(45.5)$ \\
\hline With other family/relatives & $52(6.5)$ & $83(8.3)$ & $135(7.5)$ \\
\hline In school (dormitory) & $409(50.8)$ & $4 \mid 5(4 I .3)$ & $824(45.5)$ \\
\hline In a house with other students & $4(0.5)$ & $8(0.8)$ & $12(0.7)$ \\
\hline In a house by yourself & $4(0.5)$ & $11(1.1)$ & $15(0.8)$ \\
\hline \multicolumn{4}{|l|}{ Parents leave for work } \\
\hline Yes & $388(48.2)$ & $486(48.4)$ & $874(48.3)$ \\
\hline No & $4 \mid 7(5 \mid .8)$ & $519(51.6)$ & $936(51.7)$ \\
\hline \multicolumn{4}{|l|}{ Science or Humanities Division } \\
\hline Sciences & $235(29.2)$ & $550(54.7)$ & $785(43.4)$ \\
\hline Arts & $570(70.8)$ & $455(45.3)$ & $1025(56.6)$ \\
\hline total & 805 & 1005 & 1810 \\
\hline
\end{tabular}

Table 4 Youth physical activity status according to selected independent variables ( $\bar{X} \pm \mathrm{S}$ or \%).

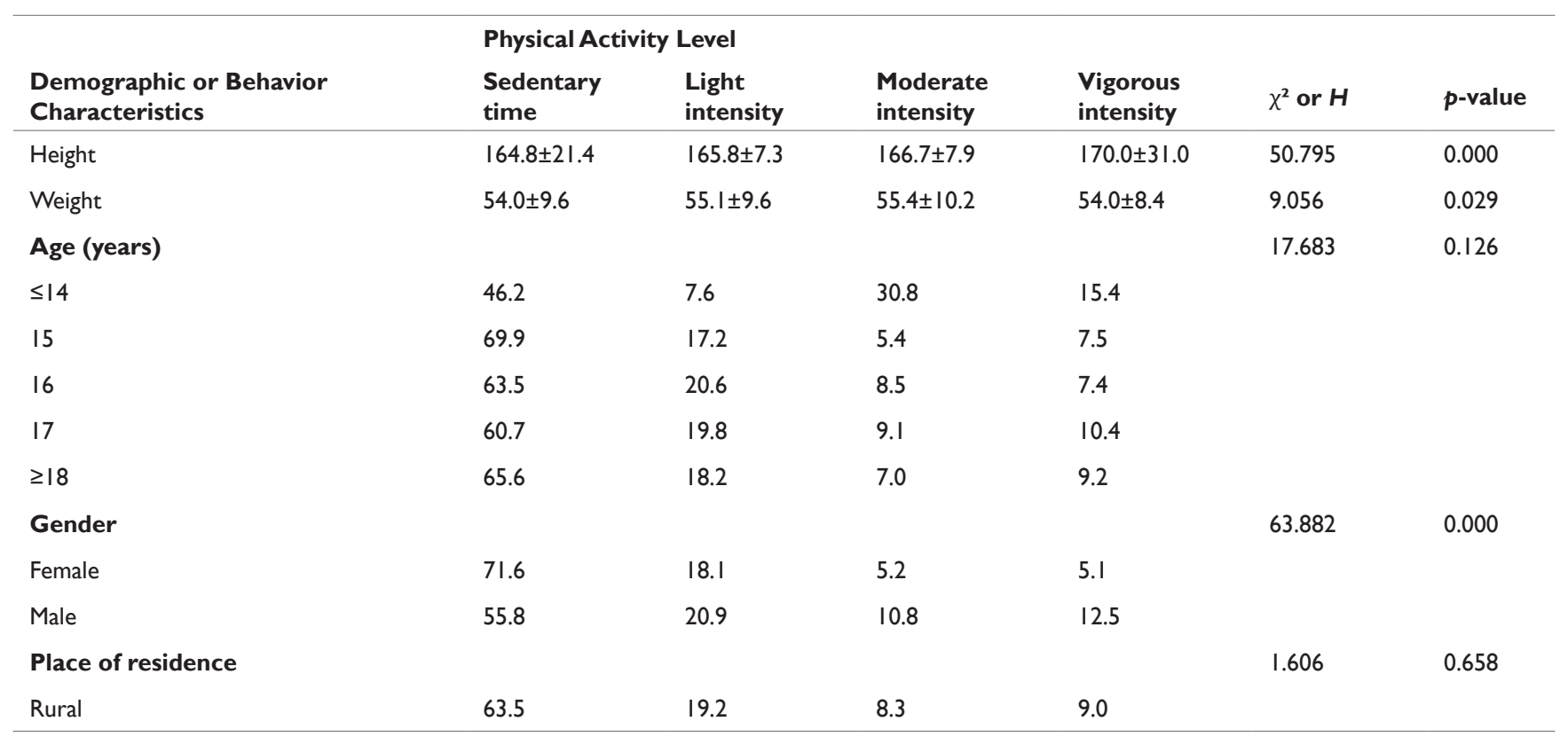


Table Continued

\section{Physical Activity Level}

Demographic or Behavior Characteristics

\begin{tabular}{llll}
$\begin{array}{l}\text { Sedentary } \\
\text { time }\end{array}$ & $\begin{array}{l}\text { Light } \\
\text { intensity }\end{array}$ & $\begin{array}{l}\text { Moderate } \\
\text { intensity }\end{array}$ & $\begin{array}{l}\text { Vigo } \\
\text { inten }\end{array}$ \\
\hline 59.8 & 21.7 & 8.7 & 9.8 \\
61.3 & 20.4 & 8.7 & 9.6 \\
63.5 & 19.0 & 8.0 & 9.5 \\
64.0 & 19.3 & 8.1 & 8.6 \\
53.8 & 15.4 & 15.4 & 15.4 \\
80.0 & 6.7 & 0.0 & 13.3
\end{tabular}

Living arrangement

With parents

With other family/relatives

In school (dormitory)

6.7

Parents leave for work

Yes

64.0

18.9

8.0

1.260

0.739

No

61.6

20.4

8.7

Science-humanities division

Sciences

62.4

18.5

9.6

3.509

0.320

Arts

63.1

20.5

Hours of learning per day

Short time

68.0

16.0

7.4

II.654

0.009

Long time

60.1

21.5

7.2

9.0

8.179

0.516

Grades over past 12 months

$\begin{array}{llll}66.6 & 17.2 & 7.4 & 8.8\end{array}$

Good grades

61.1

20.7

9.6

8.6

Average grades

62.2

20.5

7.2

10.1

Other grades

63.7

I8. I

6.9

II.3

Academic stress

Very stressed

70.0

17.9

6.5

95.847

0.000

Above average stress

63.5

19.2

8.4

5.6

Average stress

61.1

21.0

9.7

8.9

Below average stress

$51.4 \quad 23.6$

8.3

8.2

No stress

31.1

21.6

10.8

41.994

0.000

BMI Classification

Normal weight

64.2

18.9

7.6

9.3

Overweight

43.1

28.7

16.0

12.2

Obese

71.5

16.8

6.7

5.0

Table $\mathbf{5}$ Variable assignment of ordinal regression.

\begin{tabular}{lllll}
\hline Characteristics & Variable name & Factor assignment & Number & Ratio(\%) \\
\hline Physically activity & $Y$ & sedentary time=I & 1135 & 62.7 \\
& & light intensity=2 & 356 & 19.7 \\
Gender & moderate intensity=3 & 152 & 8.4 \\
& $X_{1}$ & vigorous intensity=4 & 167 & 9.2 \\
\hline
\end{tabular}




\begin{tabular}{lllll} 
Table Continued & & & \\
\hline Characteristics & Variable name & Factor assignment & Number & Ratio(\%) \\
\hline Hours of learning per day & $X_{2}$ & short time=I & 602 & 33.2 \\
& & long time=2 & 1208 & 66.8 \\
Academic stress & $X_{3}$ & very stressed=I & 513 & 28.3 \\
& & above average stress=2 & 595 & 32.9 \\
& & average stress=3 & 555 & 30.7 \\
& & below average stress=4 & 73 & 4.0 \\
BMI & no stress=5 & 74 & 4.1 \\
& $X_{4}$ & about the right weight=1 & 1446 & 79.9 \\
& & overweight=2 & 183 & 10.1 \\
& & obesity=3 & 181 & 10.0 \\
\hline
\end{tabular}

\section{Discussion}

This study was designed to investigate the relationship between overweight/obesity or academic stress and physical activity levels. The results suggested that the gender was an independent factor of high school students' physical activity. Specifically, the male participants in this study demonstrated higher physical activity level than their female counterparts; the same finding has been echoed by studies that were conducted in both China and abroad ${ }^{13,14}$ and indicates preferential differences for physical activity between genders. Male students prefer to engage in intense extracurricular physical exercise to express their youth and vitality. As adolescent girls tend to become more conscious of and pursue cosmetic beauty, they become quiet and less active, and show less interest in exercising intensely. ${ }^{15,16}$

Once adolescents reach high school they have a more mature way of thinking, study hard, and pursue their own ideals; however, the academic stress is more prominent at this age. Furthermore, they are socially inexperienced and cannot always solve the contradictions they face very well, and they may also have psychological problems. ${ }^{17,18}$ According to the results of our investigation, academic stress can affect students' participation in physical activity. The results showed that most of the students feel stress as a result of their studies $(27.9 \%$ very stressed, $33.1 \%$ above average stress, $30.9 \%$ average stress, and $4.0 \%$ below average stress stress). To achieve a premium graduation rate is the paramount task of the high school program in China due to the traditional Chinese exam-oriented education philosophy. ${ }^{19}$ Young students experience high levels of tension, anxiety, fear, and frustration when they face the stresses of frequent testing, score ranking, and the ultimate pressure of the college entrance examination. ${ }^{20}$ They also put pressure on themselves, which makes them sacrifice their leisure time to study. Consequently, their physical activity may become insufficient. ${ }^{8,21}$ Our results confirm that most students spend less time on physical exercise and more time studying. This is unfortunate because students are actually eager to take part in physical exercise and show their youth and vitality, but because of academic stress and other social and family-related factors, they have chosen to quit exercise and instead engage in numerous problem sets and practice exams. ${ }^{22}$

Epidemiological studies have shown that obesity has a certain family genetic predisposition, is not only embodied biologically but also in the tendency to be physically active. For example, if the parents like sports, their children tend to have a common love of sports as they grow older. Many studies have shown that physical activity has an important role on weight control and improving the physical quality, and the formation of childhood physical activity patterns can continue into adulthood. These have important roles in preventing chronic disease. In the past 30 years, the global (including China) incidence of childhood obesity is rising rapidly. The reduction of physical activity and an increase of a static way of life become risk factors for continuing the problem of obesity. The present study showed that students who are overweight did less physical activity.

Stress has long been suspected to be interrelated to obesity, stress may play a major role in the development and maintenance of obesity in individuals who have an increased glucocorticoid exposure or sensitivity. ${ }^{23}$ The results were consistent with previous studies that show an association between overweight/obesity and physical inactivity. According to the academic tress categories and learning time in this study, we demonstrated an inverse relationship between academic stress and physical activity. Although they know the benefits of physical activity, many Chinese students feel that they must spend most of their free time studying under the entrance examination system and are thus academically stressed; however, this study is cross-sectional and that cannot verify whether there is a causal association between academic stress and physical inactivity. Future research should explore whether these associations are maintained by observational and cohort studies.

\section{Suggestions}

The reason for adolescents' stress include "parents" and "teachers" in the study, they should be increased physical activity time at school to being integrated with changes in family lifestyle at home as well. Schools and family can have important role in preventing adolescent obesity by offering physical activities and physical education of health behavior management opportunities for students. Schools should offer or even require health education classes or provide health education lectures to expose students to knowledge about obesity, good eating habits, and the importance of physical activity to cultivate health awareness. The family should develop their personality and special skills through sports after school. Having more time and energy in their favorite sports should help students understand the importance of physical activities. If these messages can play to adolescents' subjective initiative, and teenagers participate in sports consciously, we can build a long-standing mechanism to improve the physical fitness of youth. 


\section{Conclusion}

This study described the time and the frequency of daily behaviors of high school students and revealed complex relationships between overweight/obesity or academic stress and physical activity levels among adolescents in China. More research is needed to investigate whether the associations of academic stress and physical inactivity is causal. Our findings highlight the importance of preserving time in youth schedules for physical activity every day and requiring physical education in schools as a strategy to increase overall physical activity levels and build a long-standing mechanism to improve adolescent health.

\section{Acknowledgments}

The authors would like to thank the local Center for Disease Control and Prevention and the high school in Jiangxi Province. We also express our gratitude for the teachers and students of the senior high school who participated in this site investigation. The study was part of an ongoing project of the Nevada-Nanchang University International Public Health Exchange Program.

\section{Conflict of Interest}

The authors declare there are no competing financial interests in relation to the work described. The authors declare no conflict of interest.

\section{References}

1. USDHH. Physical Activity Guidelines for Americans.; 2008. http://www. health.gov/PAGuidelines/pdf/paguide.pdf. Accessed September 3, 2018.

2. Hallal PC, Andersen LB, Bull FC, et al. Global physical activity levels: surveillance progress, pitfalls, and prospects. The lancet. 2012;380(9838):247-257.

3. Wang X, Hui Z, Terry PD, et al. Correlates of insufficient physical activity among junior high school students: a cross-sectional study in Xi'an, China. Int J Environ Res Public Health. 2016;13(4):397.

4. Duan J, Hu H, Wang G, Arao T. Study on current levels of physical activity and sedentary behavior among middle school students in Beijing, China. PloS One. 2015;10(7):e0133544.

5. Morton KL, Atkin AJ, Corder K, Suhrcke M, Van Sluijs EMF. The school environment and adolescent physical activity and sedentary behaviour: a mixed-studies systematic review. Obes Rev. 2016;17(2):142-158.

6. Trilk JL, Ward DS, Dowda M, et al. Do physical activity facilities near schools affect physical activity in high school girls? Health Place. 2011;17(2):651-657.

7. Verloigne M, Van Lippevelde W, Maes L, et al. Levels of physical activity and sedentary time among 10-to 12-year-old boys and girls across 5 European countries using accelerometers: an observational study within the ENERGY-project. Int J Behav Nutr Phys Act. 2012;9(1):34.

8. Cooper AR, Goodman A, Page AS, et al. Objectively measured physical activity and sedentary time in youth: the International children's accelerometry database (ICAD). Int J Behav Nutr Phys Act. 2015;12(1):113.
9. Hanna CL, Laflamme L, Elling B, Möller J. Unlicensed driving and other related health risk behaviors: A study of Montana high school students. Accid Anal Prev. 2013;54:26-31.

10. Collings PJ, Wijndaele $\mathrm{K}$, Corder $\mathrm{K}$, et al. Levels and patterns of objectively-measured physical activity volume and intensity distribution in UK adolescents: the ROOTS study. Int J Behav Nutr Phys Act. 2014;11(1):23.

11. Gray C, Gibbons R, Larouche R, et al. What is the relationship between outdoor time and physical activity, sedentary behaviour, and physical fitness in children? A systematic review. Int J Environ Res Public Health. 2015;12(6):6455-6474.

12. Perry CK, Saelens BE, Thompson B. Intrapersonal, Behavioral and Environmental Factors Associated With Meeting Recommended Physical Activity Among Rural Latino Youth. Pediatr Exerc Sci. 2011;23(4):521536.

13. Arundell L, Fletcher E, Salmon J, Veitch J, Hinkley T. A systematic review of the prevalence of sedentary behavior during the after-school period among children aged 5-18 years. Int J Behav Nutr Phys Act. 2016;13(1):93.

14. Chen Y, Zheng Z, Yi J, Yao S. Associations between physical inactivity and sedentary behaviors among adolescents in 10 cities in China. BMC Public Health. 2014;14(1):744.

15. Beets MW, Okely A, Weaver RG, et al. The theory of expanded, extended, and enhanced opportunities for youth physical activity promotion. Int $J$ Behav Nutr Phys Act. 2016;13(1):120.

16. Lonsdale C, Lester A, Owen KB, et al. An internet-supported physical activity intervention delivered in secondary schools located in low socio-economic status communities: study protocol for the activity and motivation in physical education (AMPED) cluster randomized controlled trial. BMC Public Health. 2015;16(1):17.

17. Hoare E, Milton K, Foster C, Allender S. The associations between sedentary behaviour and mental health among adolescents: a systematic review. Int J Behav Nutr Phys Act. 2016;13(1):108.

18. Wijsbroek SA, Hale III WW, Raaijmakers QA, Meeus WH. The direction of effects between perceived parental behavioral control and psychological control and adolescents' self-reported GAD and SAD symptoms. Eur Child Adolesc Psychiatry. 2011;20(7):361-371.

19. McGregor BA, Murphy KM, Albano DL, Ceballos RM. Stress, cortisol, and B lymphocytes: a novel approach to understanding academic stress and immune function. Stress. 2016;19(2):185-191.

20. Wu LJ, You QS, Duan JL, et al. Prevalence and associated factors of myopia in high-school students in Beijing. PLoS One. 2015;10(3):e0120764.

21. Schoeppe S, Duncan MJ, Badland HM, Oliver M, Browne M. Associations between children's independent mobility and physical activity. BMC Public Health. 2014;14(1):91.

22. Li M, Dibley MJ, Yan H. School environment factors were associated with BMI among adolescents in Xi'an City, China. BMC Public Health. 2011;11(1):792.

23. van der Valk ES, Savas M, van Rossum EF. Stress and Obesity: Are There More Susceptible Individuals? Curr Obes Rep. 2018;7(2):193-203. 